\title{
Parte 2 - Quase Homem, Quase Mulher: as repercussões na rede social Facebook de gênero e sexualidade trans da publicidade veiculada na televisão aberta brasileira
}

\author{
André Iribure \\ Universidade Federal do Rio Grande do Sul
}

\section{Resumo}

Este texto é recorte de pesquisa iniciada em 2009, com corpus de 122 comerciais veiculados em TV Aberta, que abordam a temática LGBTQIA+. A pesquisa estrutura-se entre análise das representações em TV e das repercussões de parte desses comerciais na rede social Facebook. Aborda-se, neste momento, mais especificamente, um recorte sobre o tipo de engajamento dos comerciais que tiveram repercussões nas páginas das marcas e que aludem à temática ou a personagens trans, a letra T da sigla apresentada, num total de cinco comerciais. As peças publicitárias, no geral, tiveram repercussão positiva, gerando engajamento com seu público, apesar de comentários que reagem negativamente, com argumentos de cunho religioso em sua maioria, e outros com críticas afora da temática em questão.

\section{Palavras-chave:}

LGBTQIA+. Publicidade. Gênero. Sexualidade. Representações.

\section{Introdução}

No cenário atual ${ }^{1}$, numa visão macro, percebemos alguns avanços significativos nas conquistas de direitos civis para os sujeitos que tensionam o modelo hegemônico da heteronormatividade que, por muito tempo, foram colocados à margem. Porém, esses avanços ainda são questionados por segmentos da sociedade que se impõem a partir de modelos hegemônicos, a autorizarem falas e a colocarem aquém, nas relações de poder, elementos que escapam e tensionam a diversidade de construções identitárias não normativas.

Essas identidades que escapam a modelos tomados como norma, em contradição a uma perspectiva social e histórica, a partir da contribuição dos estudos de gênero, foram silenciadas, até final do século XIX. Elas se mostraram timidamente no movi-

1 Trabalho apresentado no GP Publicidade e Propaganda, XVIII Encontro dos Grupos de Pesquisas em Comunicação, evento componente do $41^{\circ}$ Congresso Brasileiro de Ciências da Comunicação.

Revista Ícone (ISSN 2175-215X) • DOI: 10.34176/icone.v17i2.241224

Recife, Vol. 17, N. 2, 93-106, ( 2019 PPGCOM/UFPE.

Artigo recebido em 12 dez. 2018 e aprovado em 7 fev. 2019. 
mento homófilo de início do século XX, ganharam fôlego com o avanço dos questionamentos do movimento feminista, e culminaram na perspectiva política da sexualidade na virada para os anos 1970.

Contudo, essa visibilidade teria um capítulo perverso na história. Tempos atrás, décadas de 1980 e 1990, com o advento da AIDS, as práticas homossexuais ganharam notoriedade, num primeiro momento para chamar atenção para o impacto dos que manifestavam a doença fisicamente, e num segundo momento para as formas de prevenção através de políticas públicas do estado. De forma sem precedentes, a AIDS obrigou a sociedade a falar de sexo e, mais, de sexualidades não normativas (TREVISAN, 2004). Não obstante, a mídia, que vinha, até então, timidamente traduzindo as vozes marginais, teve em suas editorias a inserção da temática que assolava o espaço privado, do que se tinha da família monogâmica heteronormativa como modelo.

Através de olhares de reprovação, por um tempo, a doença foi chamada de Câncer Gay, referindo-se assim a uma camada da sociedade que por subsequência era entendida como a disseminadora da doença. Neste contexto, enquanto a sociedade "crucificava" homens gays, travestis e profissionais do sexo, que eram os principais portadores da doença, na época chamados do grupo de risco - hoje entendido como comportamento de risco - o Estado tentava entender e definir estratégias de como amparar essas pessoas e parar o avanço da doença. Por um lado, com a aproximação do Estado desse público vulnerável socialmente, diante desse cenário, começaram a surgir discussões sobre os direitos sexuais dessas minorias.

Neste ano, está acontecendo um dos eventos esportivos de maior visibilidade mundial, a Copa de Mundo de 2018, em um dos países onde os direitos das pessoas LGBTQIA $+{ }^{2}$ ainda são desrespeitados. A Rússia é um país em que a manifestação pública homoafetiva ainda é passível de punição, não obstante os turistas brasileiros foram alertados, pelo Governo Federal ${ }^{3}$, para não demonstrar nenhum tipo de afeto que pudesse ser entendido como não normativo, pois as leis do país são extremamente rígidas. O simples ato de sair carregando ou vestindo a bandeira do movimento LGBTQIA+ pode ser suscetível a pena nas leis nesse país.

A conjuntura social e política do Brasil perante os direitos humanos dos LGBTQIA+ está mudando aos poucos. É relevante que sejam ressaltadas algumas conquistas a ampliarem a percepção da sexualidade na perspectiva da inclusão social e de respeito à diversidade desde a possibilidade de adoção, protegida pela Constituição Federal de 1988 que não faz menção a orientação sexual do adotando, à equiparação da união civil estável entre pessoas do mesmo sexo às uniões entre homens e mulheres, aprovada pelo STF em 2011, assim como a retirada da Homossexualidade da Classificação Internacional de Doenças (CID) em 1990 e, a última conquista de grande repercussão, a exclusão da transexualidade da lista de doenças mentais na CID, neste ano. Essas

2 A sigla refere-se a Lésbicas, Gays, Bissexuais, Trangêneros/Transexuais, Queers, Intersexo, Assexuais/Agênero e + todas as outras orientações que escapam ao modelo heteronormativo, entendidos como não normativos, minorias sexuais, e, em alguns momentos, tomados como sinônimos de homossexualidades, no plural.

3 Guia Consular do Tocedor Brasileiro - Copa do Mundo 2018 (https://tinyurl.com/y34p4s54). 
transformações se devem às lutas do movimento LGBTQIA+ que tensiona o Estado para que hajam mudanças permanentes e condizentes para os direitos humanos e civis dessas pessoas.

Não muito distante, no contexto da mídia, percebe-se que a publicidade compreende a diversidade social a incluir novos potenciais consumidores, e, ao mesmo tempo, entende que precisa representar essa nova parcela social - sem desagradar os setores mais conservadores. Nesse meio, ficam os anunciantes e as agências de publicidade que enfrentam o desafio de falar para todos os públicos. Para analisar esse contexto em que a publicidade encontra-se, a pesquisa compreende que os corpos, assim como as identidades de gênero e sexuais, não são condicionados apenas biologicamente; mas sim, significados pela cultura e alterados continuamente por ela. Portanto, é necessário que se compreenda a complexidade das construções identitárias, para além de um modelo único, tendo como referencial uma perspectiva pós-estruturalista que se vale de um olhar desconstrucionista.

E, é nesse contexto que este trabalho está inserido com o intuito de acompanhar o discurso que aborda a temática das minorias sexuais na publicidade televisiva e suas repercussões em redes sociais. Mais precisamente, neste artigo, os textos que discorrem sobre a temática Trans, porque interessa identificar como a publicidade, em texto e imagem, se utiliza de representações sociais em suas estratégias mercadológicas nas construções identitárias e sexuais dos que escapam ao modelo heteronormativo. A TV Aberta é percebida como meio massivo que demonstra o que pode ser dito à sociedade, e, de forma mais contemporânea, as redes sociais permitem identificar o engajamento com a temática do que foge à norma. Para isso, o artigo propõe uma análise das repercussões das transexualidades na rede social facebook dos anunciantes, através da análise de quatorze comerciais veiculados na televisão aberta brasileira, analisado o tipo de engajamento nesse ambiente dialógico e digital.

Este texto avança, na pesquisa a seguir apresentada, sendo um recorte, e continuidade de texto apresentado no IX Encontro Nacional de Pesquisadores em Publicidade e Propaganda. ${ }^{4}$

Portanto, os objetivos deste texto se inserem nos da pesquisa e que se sintetizam a seguir: identificar as representações LGBTQIA+ na publicidade veiculada em TV aberta, sincrônica e diacronicamente; evidenciar como essas representações, através do texto publicitário, entram em disputa com o modelo hegemônico; na segunda etapa da pesquisa, no recorte deste texto, identificar o potencial de repercussão dessa temática na rede social Facebook dos anunciantes, a partir de material veiculado em TV aberta, com expectativa de identificar o tipo de engajamento de públicos com anunciantes. Metodologicamente, como referenciais, a produção está baseada nos Estudos de Gênero e da Sexualidade, numa perspectiva dos estudos Queer, nas Representações Sociais - dos Estudos Culturais e da Psicologia Social, no contexto da publicidade, e na

4 Trabalho apresentado no VII Colóquio de Pesquisadores em Publicidade intitulado Quase homem, quase mulher: as representações do gênero e da sexualidade em personagens trans na publicidade veiculada na televisão aberta brasileira. Disponível em http://www.abp2.org/copy-of-about-me acessado em julho de 2018. 
Análise de Conteúdo das Representações, tanto na TV Aberta quanto na Rede Social Facebook. Tem-se a expectativa de problematizar e compreender em que medida a publicidade contribui para a visibilidade das representações trans, a partir do que se percebe no tipo de engajamento dos usuários de rede social, e quais os limites identificado num capital social construído em ambiente digital.

Neste contexto, o termo Trans se refere a tudo o que transcende o binarismo sexual e de gênero, compreendendo transexuais, travestis, intersexuais, Drag Queen/ Kings e demais possibilidades de desconstrução que a todo momento nos desafiam a pensar na pluralidade das identidades de gênero e sexuais.

\section{A pesquisa: entre as representações e os engajamentos}

Com os direitos LGBTQIA+ na pauta das discussões contemporâneas, a publicidade percebeu, ou em muitos aspectos foi pressionada, nos últimos tempos a ir além de posturas comumente abordadas, fazendo com que as marcas estejam a cada dia mais atentas e em sintonia com as mudanças sociais.

De acordo com o estudo TodXS - uma análise da representatividade na publicidade brasileira realizado pela a agência Heads, em 2016, boa parte dos filmes publicitários que rompem com os estereótipos de gênero são publicados em plataformas digitais - onde estão os indivíduos mais jovens e com tendências menos conservadoras - ao invés de serem veiculados em TV aberta - onde ainda está concentrada a maior parte da população. O resultado do estudo revela que a publicidade exibida tanto na TV quanto nas plataformas digitais, de maneira geral, ainda reforça estereótipos e não representam a diversidade de raça, gênero e sexualidade da sociedade ${ }^{5}$.

Hoje os anunciantes contam com profissionais de pesquisas de mercado e pagam preços significativos para seu comercial falar e mostrar nas telas dos lares da família brasileira - para além de uma novela ou programa de grande audiência - lésbicas, gays, bissexuais e trans no espaço comercial.

Nos últimos anos, nota-se um crescente no número de peças e campanhas publicitárias que abordam a questão das sexualidades não normativas, o que sugere pesquisas que analisem os tensionamentos nos tipos de representações deste segmento da sociedade. Na pesquisa iniciada em 2009, intitulada "Estudos de Gênero e da Sexualidade na Publicidade e Propaganda Brasileira: as representações das homossexualidades em anúncios publicitários televisivos" iniciou-se uma análise sobre as peças publicitárias que tiveram como mote essa temática.

A pesquisa, numa primeira etapa, tem como base o levantamento e mapeamento dos comerciais, pois a partir deles pode-se obter um panorama das representações não normativas de gênero e da sexualidade, que acontecem ao longo desses anos na publicidade brasileira veiculada na TV Aberta que a pesquisa abarca, quase 04 décadas, de 1979 até 2018. Dessa forma, como postado anteriormente, visa-se entender como o discurso publicitário vem se apropriando e mediando culturalmente um grupo que

5 Disponível em: <https://pt.slideshare.net/mediaeducation/todxs-uma-anlise-da-representatividade-na- publicidade-brasileira> Acesso em outubro de 2017. 
adquire visibilidade social e na mídia, aliado a conquistas de direitos civis.

O corpus da pesquisa é composto de 122 peças publicitárias veiculadas em TV Aberta, que abordam a temática LGBTQIA+. Para estudo do corpus fez-se necessário categorizar as peças publicitárias, para uma primeira análise das representações, como estratégia metodológica em dois grupos: Estereotipados, que reafirmam o modelo hegemônico e Desconstrucionistas, que tensionam o padrão vigente (Rodrigues, 2008).

Categorizados como Estereotipados identificam-se os comerciais que seguem a conduta de estigmatizar uma parcela da sociedade, inserindo-a em uma relação de poder que a inferioriza e desvaloriza, acionando a inserção de estereótipos. A desvalorização ou redução a um atributo que entra em tensão com a norma impede que a homossexualidade entre em confronto com o elemento principal do modelo hegemônico, com a norma heterossexual. Sendo assim, os personagens-mote são incorporados como participantes da lógica da norma heterossexual ao reforçar estereótipos que delimitam o que é variante dessa norma, sendo inseridos sob a regulação do que dizem, pensam, vestem, pelo cenário, locução, sons e interpretação. O discurso reduz esses personagens a elementos para chamar atenção, muitas vezes de maneira risível, ao mesmo tempo que garante as fronteiras da "normalidade".

Já os Desconstrucionistas mostram novas vivências da sexualidade que não seguem necessariamente enquadradas num modelo heteronormativo, mostrando formas alternativas e superando expectativas do que é visualizado entre os personagens tradicionais. Mesmo que regulada sobre o que pode ser tornado público das homossexualidades, há um tensionamento dessas representações, amparadas na alteridade do que escapa da norma. Por isso, manifesta diferentes possibilidades de criação dos personagens-mote, amparadas nas alterações sociais provocadas por uma parcela da sociedade que reivindica sua inserção social.

As categorias utilizadas na pesquisa foram uma estratégia metodológica para que permitam a leitura das peças publicitárias. Contudo, admite-se que os comerciais podem transitar entre um modelo e outro, não sendo, portanto, limitados a uma categoria específica.

Nesta primeira etapa também utiliza-se, para estudo dos comerciais, como técnica de tratamento dos dados fichamento, descrição, decupagem e análise de cada peça.

Através das fichas, é possível identificar os profissionais envolvidos na produção dos filmes publicitários; seguidas da descrição que, como o nome sugere, descreve as peças; acompanhado de decupagem que reforça e ilustra a descrição, e finalizada com a análise propriamente dita dos comerciais (Rodrigues, 2008).

Uma vez que a pesquisa atinge um número significativo de análise das representações, mostrou-se relevante avançar para sua segunda etapa. Interessa-nos mapear o nível do que se considera, para esta pesquisa, engajamento ${ }^{6}$ dos consumidores e das

6 Compreende-se engajamento como o resultado de Interações Mútuas (PRIMO, 2003) entre duas ou mais pessoas, em ambiente digital, seguidas da criação de Laços Fortes que gerem Capital Social entre as mesmas, ou seja, a troca de informações sobre assuntos de interesse em comum aos envolvidos (RECUERO, 2014). Ver mais em RODRIGUES, A. I.; TOALDO, M. M. Interação e Engajamento entre Marcas e Consumidores/Usuários no Facebook (2015). 
marcas no ambiente digital, com relação aos comerciais veiculados em TV Aberta, posteriormente postados nas páginas das respectivas marcas. É a partir do ano de 2015, com o lançamento do comercial de Dia dos Namorados, da marca O Boticário, que os comerciais analisados começam a ser observados também em plataforma digital, na Rede Social Facebook.

A metodologia aplicada nesta fase considera o número de visualizações dos comerciais, os compartilhamentos, as reações e os comentários. Com base nestes dados avançamos para a montagem da tabela de Matriz de Interagentes e para o gráfico comparativo de dados.

A Matriz de Interagentes é fundamentada, principalmente, nos estudos de Recuero $(2005,2014)$ a fim de compreendermos os impactos e alterações da relação entre marca e consumidor através da comunicação via redes sociais, de forma dialógica por interagentes. Assim como compreender a formação do engajamento por meio da formação de laços sociais e de capital social.

Os laços sociais são compostos por laços fortes e laços fracos, sendo respectivamente, laços fortes trocas mútuas e constantes, com relacionamento emocional envolvido, entre grupos conversacionais (interação mútua); já os laços fracos são as relações casuais sem compromisso com a troca de informações, de forma limitada ao prescrito pela plataforma (interação reativa). O capital social por sua vez é o resultado destas transações juntamente com a discussão de valores relacionada ao assunto, neste caso o LGBTQIA +, ou seja, é o debate acerca das interações e dos laços criados entre os interagentes.

O gráfico Comparativo de dados mostra de forma sucinta quais foram os principais comportamentos, de cada público, perante a publicação da marca, nele são confrontados os comentários, os compartilhamentos e as reações. Os comentários e reações são analisados de forma quantitativa, ou seja, o que importa são os números atingidos em cada publicação da marca com a temática.

Para analogia dos comentários utiliza-se a categorização de forma qualitativa, pressupondo identificar quais comentários são Desconstrucionistas, Estereotipados, já supracitados neste artigo, e No Armário, esta última surge para complementar a análise, preenchendo as lacunas deixadas pelas categorias anteriores.

Comentários classificados como No armário são os que somente citam outras pessoas, que não geram nenhuma discussão plausível ou usam algum tipo de linguagem (emoticons, memes, etc.) que ficam dúbios para entendimento nas outras categorias.

\section{A quantas andam os engajamentos}

A pesquisa conta com 14 peças publicitárias ${ }^{7}$ que contemplam a letra $\mathrm{T}$ da sigla

7 Bombril - Quase de Graça 1999, Correios - Cartões de Natal 2000, Snickers Brasil - República 2013, Bom Negócio - Cristaleira Rogéria 2014, Bob's - Favorzinho 2014, Ministério da Saúde - Campanha Contra AIDS 2014, Nova Schin - Maria Bonita 2015, CEDS Rio - A Aids não tem cara nem tem cura 2015, Snickers Brasil - Vestiário 2015, InstaLove Gang - 2016, Avon - True Base Líquida Matte 2017, 
LGBTQIA+, sendo o primeiro deles datado do ano de 1999. Hoje com as redes sociais estes comerciais ganham mais força, assim como atingem um público cada vez mais significativo. Destes catorze comerciais, cinco estão na rede social de suas respectivas marcas e passaram pela primeira e segunda etapa da pesquisa, sendo eles: Gang Instalove (2016); Avon True Base Líquida Matte (2017); Avon Máscara Supreme de 2017; Doritos (2017); Tudo começa pelo respeito - campanha contra a transfobia (2018).

Gang Instalove (2016) considerado pela pesquisa como Desconstrucionista, teve mais de 60 mil visualizações, 90 compartilhamentos e 605 reações. O comercial trata de maneira bastante natural relacionamentos que fogem do padrão heteronormativo ao sugerir uma relação entre Roberto e Lucas, além de deixar clara sua posição contrária aos estereótipos de gênero através do personagem-mote ${ }^{8}$ Lucas. A peça divulga a promoção lançada pela Gang, na semana do Dia dos Namorados de 2016. Os casais representam potenciais casais da vida real. De maneira jovem e descontraída, a peça trata de maneira natural as questões sobre sexualidade e identidade de gênero que, de maneira positiva, quase não se percebe.

Na publicação da marca aparecem muitos comentários de pessoas marcando outras, os denominados No Armário. Seguem-se os comentários Desconstrucionistas que apoiam a campanha da marca de roupas. Nesta publicação não houve nenhum comentário Estereotipado.

A peça publicitária Avon True Base Líquida Matte (2017) não pode ser feita a devida análise de dados, pois a marca retirou de sua página na rede social, Facebook, o vídeo. Considera-se a peça como Desconstrucionista, pois, a partir da análise das representações - primeira etapa da pesquisa - e mesmo sem os dados da rede social, pode- se perceber que a marca tem o intuito de celebrar a diversidade feminina e enaltecer a coragem das mulheres que desafiam preconceitos, lançando assim sua nova campanha com tema "Cara e Coragem". A ação lança os produtos de maquiagem da marca Avon True, e mostra a maquiagem como mais um elemento para as mulheres valorizarem suas identidades e estarem seguras diante dos desafios do cotidiano.

Já em sua peça Avon Máscara Supreme (2017), que segue em sequência a peça anterior, para apresentar outra maquiagem, desta vez o rímel, a marca convida as mulheres a "enfrentar o mundo olhando para frente", na campanha de lançamento dos produtos traz, mais uma vez, como uma de suas protagonistas a cantora transexual Candy Mel. Em muitos comentários, na postagem da marca em sua página, internautas nem a percebem como trans. A publicação obteve 11 mil compartilhamentos, 93 mil reações e 4,8 mil visualizações.

O engajamento maior nesta publicação foram de comentários No Armário, muitas pessoas que comentavam estavam interessadas em saber quem vendia a máscara de cílios, assim como percebeu-se muitas consultoras apresentando seu trabalho. Os comentários Estereotipados estavam relembrando uma postagem da marca na campanha "Repense o elogio", anterior a esta analisada, onde a Avon se posiciona para os pais

Avon - Máscara Avon Supreme 2017, Doritos - Rainbow 2017, Globo - Tudo Começa pelo respeito 2018.

8 Personagem que tensiona e mobiliza a temática dos que fogem ao padrão heteronormativo. 


\section{Engajamento}

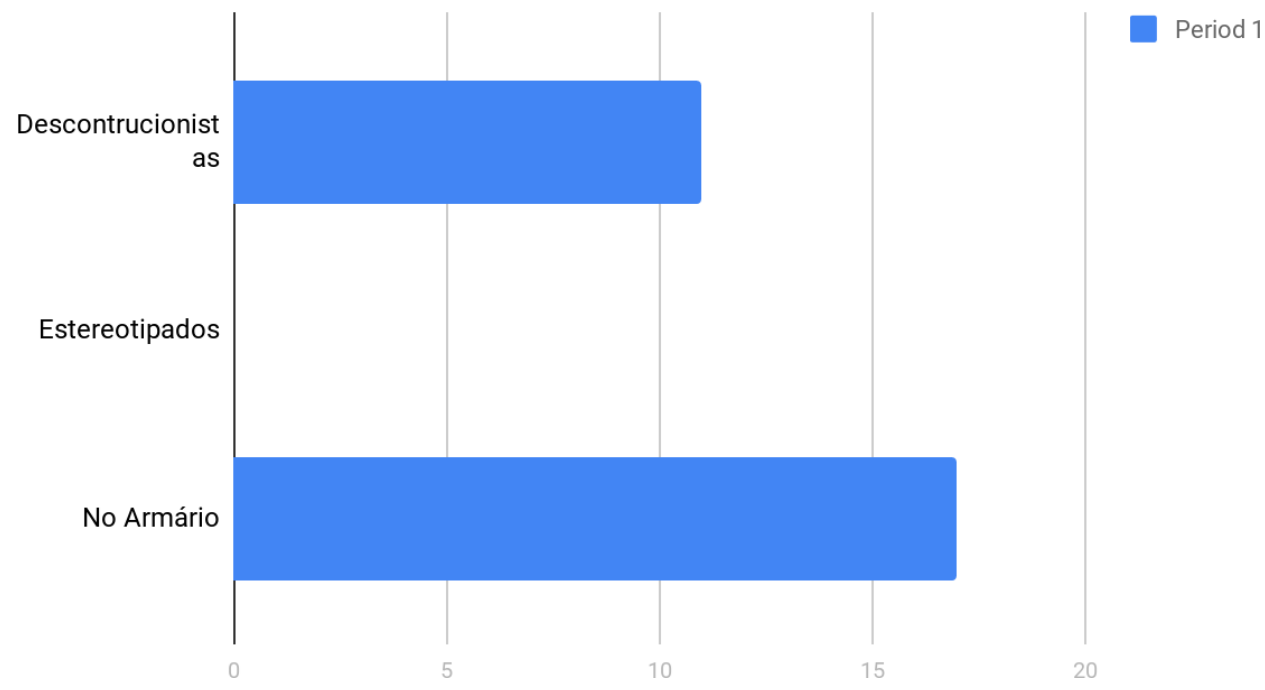

Gráfico 1 - Gang. Produzido pelo autor.

\section{Engajamento}

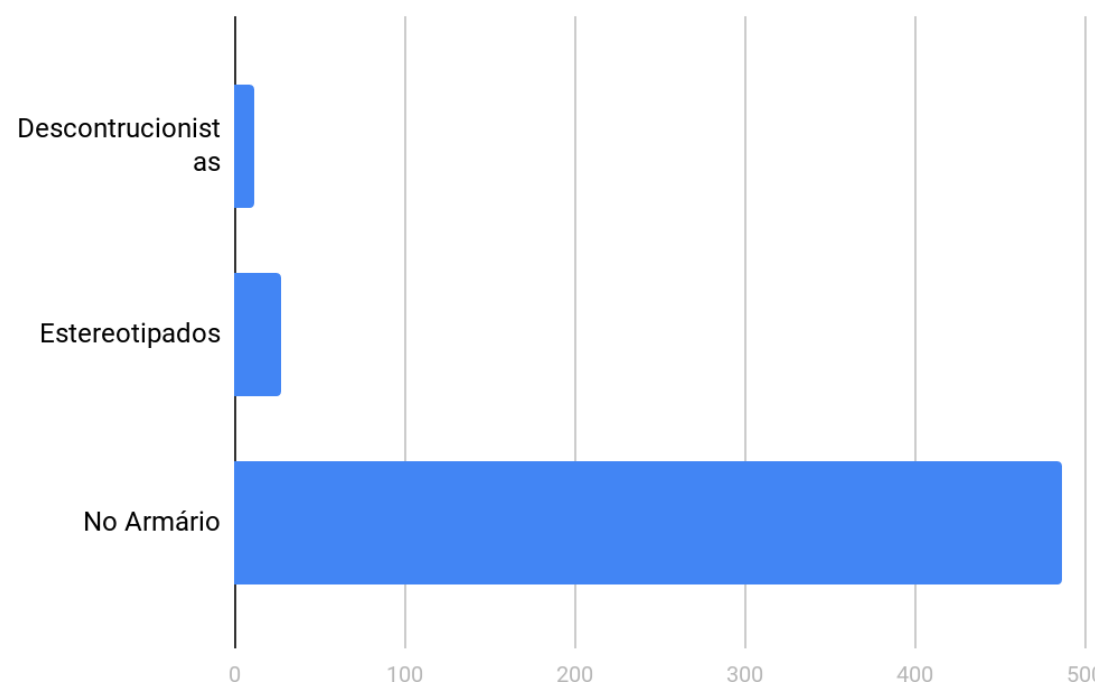

Period 1

Gráfico 2 - Avon. Produzido pelo autor. 
em relação a forma como elogiam seus filhos. A postagem com a cantora Candy Mel trouxe à tona lembranças e críticas à postagem anterior, alguns internautas comentaram que era "apologia a troca de sexo, por isso não podiam mais chamar suas filhas de princesas" alguns postaram que iriam boicotar a marca que é "contra a família tradicional". A maioria desses comentários foram alvejados pelo público Desconstrucionista através de discussões e, até, de memes.

A marca de salgadinhos Doritos (2017), teve 113 mil reações, 9.209 compartilhamentos e 9,5 mil visualizações. Mostra um vídeo que tem o claro intuito de trazer referências históricas do movimento LGBT, quando busca resgatar as cores da primeira bandeira do movimento criada em 1978 e traz na trilha sonora a música True Colors, que foi lançada em 1986 pela cantora Cindy Lauper e que teve essa música considerada durante muito tempo como um hino para a comunidade LGBT. Ao longo de todo vídeo, também nota-se como o conceito da campanha "Mais cores. Mais diversidade. Mais empoderamento." está alinhado com o que é mostrado, para além da questão da sexualidade. No início a campanha foi lançada, principalmente, para alcançar o público da Parada LGBT de São Paulo e o Festival Milkshake, em que se pode notar que questões como raça e gênero também foram abordadas, o que não só demonstra a pluralidade que há dentro do movimento, mas também a importância da representatividade e da visibilidade destes personagens estarem protagonizando a campanha.

Doritos teve grande repercussão dos comentários Desconstrucionistas. Pode-se perceber que grande parte do público conhecia a Drag Queen que estava na peça. Os comentários No Armário pediam informações de cidades onde o produto era vendido e os comentários Estereotipados vinham com frases aludindo aos "bons costumes e valores", assim como, "boicote" à marca.

Por fim, dos últimos comerciais levantados, a emissora de televisão, Rede Globo, atingiu 15 mil compartilhamentos, mais de 10 mil visualizações e 35 mil reações com seu comercial intitulado Tudo começa pelo respeito - campanha contra a transfobia (2018), que visa mostrar que pessoas trans possuem várias qualidades sublimadas pelo preconceito e que é necessário conversar e respeitar a diversidade.

No mote do respeito à diversidade a publicação da Rede Globo em geral foi bem aceita perante o público na sua rede social. Muitos comentários Desconstrucionistas elogiando a coragem da marca e fazendo alusão a novela Força do Querer, novela das $21 \mathrm{~h}$ que estava sendo veiculada na emissora quando a peça foi lançada, com uma personagem trans. Os comentários Estereotipados também relembraram a novela, porém de forma depreciativa, muitos comentários disseram ser contra a emissora e que sua família, na grande maioria citava apenas os filhos, não poderiam ver a novela pois não entenderiam o que estava acontecendo, no caso estavam falando sobre as mudanças da personagem.

Após analisar cada uma das peças publicitárias individualmente, observando a reação dos públicos envolvidos, pode-se chegar ao gráfico abaixo em que se compara os cinco comerciais de forma geral com base nos dados de Compartilhamentos, Reações, e Comentários. Logo após, mostra-se o gráfico que compara de forma quantitativa os cinco comerciais na perspectiva de engajamento nos comentários, sendo assim, 


\section{Engajamento}

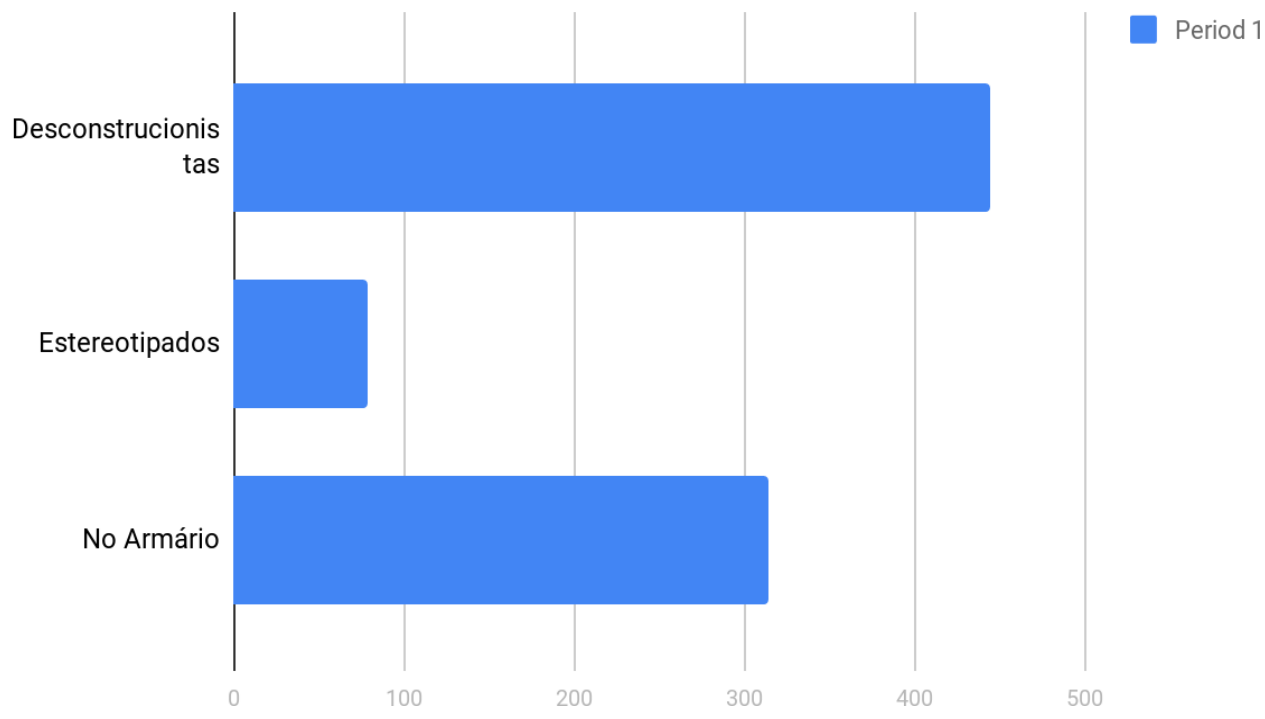

Gráfico 3 - Doritos. Produzido pelo autor.

\section{Engajamento}

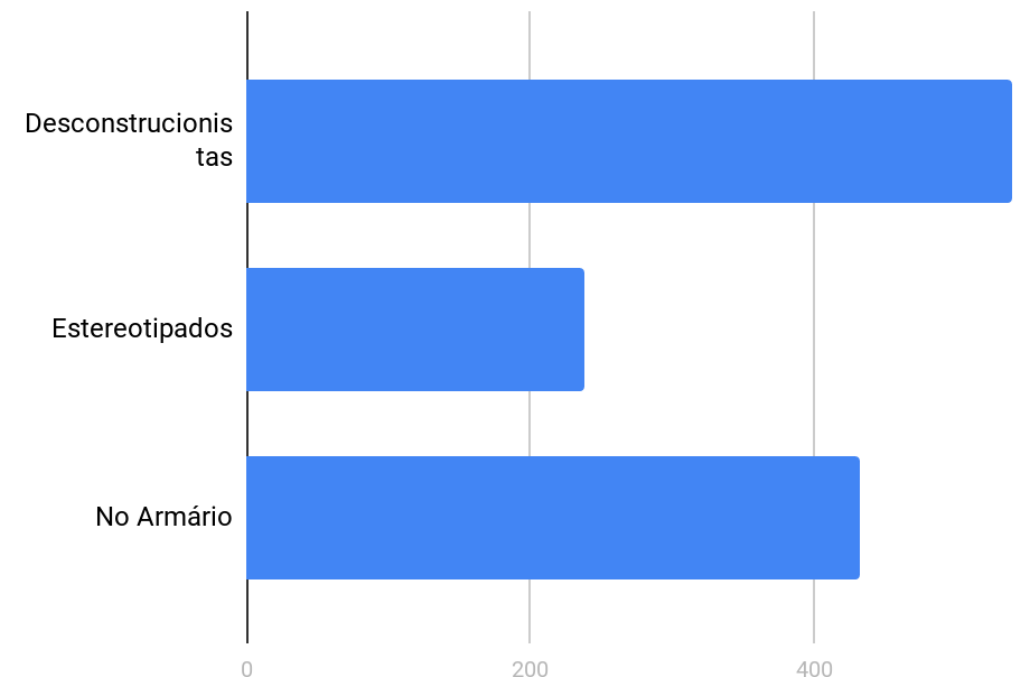

Gráfico 4 - Globo. Produzido pelo autor. 
comparamos os Desconstrucionistas, Estereotipados e No Armário de forma geral. Os dados quantitativos e qualitativos da pesquisa são um resultado de uma semana de coleta de informações na página de cada marca, na rede social Facebook. Limita-se a sete dias desde a postagem do comercial pela marca.

Percebe-se nestes comerciais que há um grande número de comentários No Armário, principalmente na marca de cosméticos, de pessoas que não perceberam a disrupção presente em cada frame do vídeo quando mostra uma mulher trans usando maquiagens e sendo alvo de olhares admirados perante formas alternativas de construção identitária a partir do gênero e da sexualidade.

A marca de alimentos e a rede de televisão mostram uma aceitação perante o público Desconstrucionista que comentam de forma positiva e, por muitas vezes, entram em debate, nem sempre amigável, com os comentários do público Estereotipado que, por sua vez, reforçam a ideia de heteronormatividade. Nesse caso, os interagentes demonstram um nível de engajamento com construção de capital social com o anunciante.

\section{Considerações Finais}

Dos comerciais identificados para esta pesquisa compreende-se que cada um tem seu público distinto entre si, mesmo que as peças tenham como pauta em comum a diversidade. As estratégias de campanha e os diferentes segmentos impõem para cada marca uma narrativa singular. Entende-se que a estratégia que algumas agências estão tomando para incluir as várias formas de se construir para além de modelos heteronormativos está a contribuir para um tensionamento na sociedade, a repensar modelos, pois percebe-se essa tensão nos comentários observados em cada postagem.

De maneira geral, os comentários Desconstrucionistas são sempre carregados de uma perspectiva de direitos humanos e civis, bem como, o apoio à diversidade. Em alguns comentários identifica-se uma perspectiva do movimento LGBTQIA+ mostrando que todas as pessoas precisam ser respeitadas. Os comentários Estereotipados, em sua maioria, se embasam na ideologia religiosa, muitos escrevem citações bíblicas para corroborar seu pensamento contra as várias maneiras de se existir. Os No Armário são os comentários que, de modo geral, não pendem para um lado nem para o outro. São em sua maioria marcações e em algumas marcas os questionamentos que fazem na publicação fogem à temática demonstrando pouco ou nenhum interesse ao que está sendo mostrado.

A pesquisa entende que ainda há avanços pertinentes para serem colocados em pauta pela publicidade, porém não há como negar o progresso que se tem até o momento. Em uma sociedade que lidera o ranking de mortes a pessoas transexuais, onde a cada 48 horas uma pessoa trans é assassinada, estar na televisão e se mostrar como parte de uma sociedade, que ainda relega à invisibilidade social, é uma significativa contribuição com a crítica à heteronormatividade imposta e tomada como norma padrão de conduta. 


\section{Gráfico Comparativo Geral}

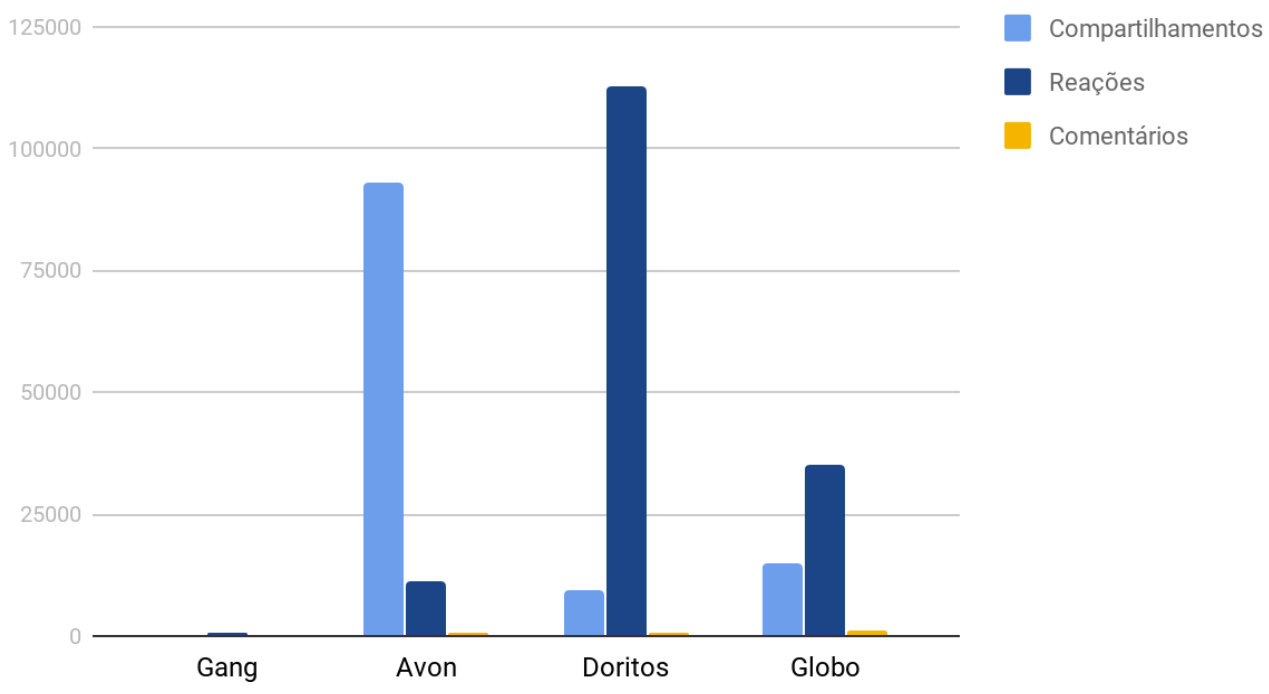

\section{Gráfico Comparativo Engajamento}

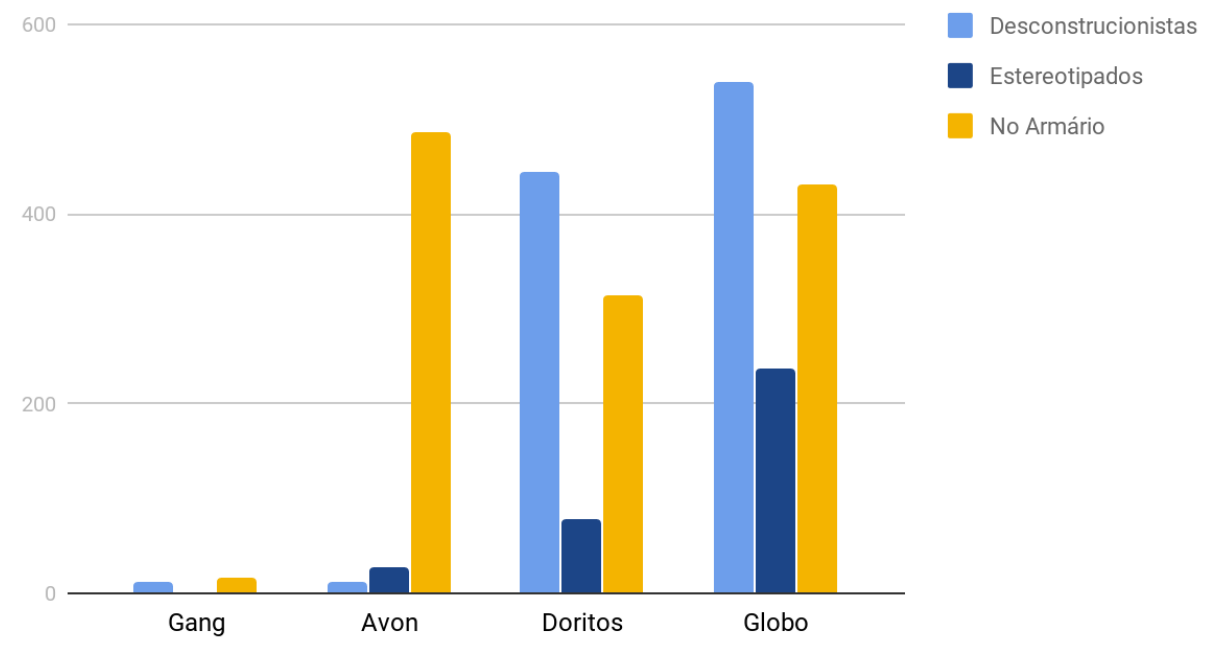

Gráfico 5 - Gráfico Comparativo Geral e Engajamento. Produzido pelo autor. 


\section{Referências}

CONNELL, Robert William. Masculinidades. Trad. Irene M. Artigas. México: UNAM/PUEG, 2003. cap. 3,p. 103/129-cap.8-9, p. 249/302.

CONNELL, Robert William. Políticas da Masculinidade. Educação \& Realidade, Porto Alegre, v. 20, n. 2, 185-206, jul/dez. 1995

BAUER, Martin W. Análise de Conteúdo Clássica: uma revisão. In: Bauer, Martin; GASKEL, George (editores). Pesquisa Qualitativa com texto, imagem e som: um manual prático. Trad. Pedrinho A. Guareschi. Petrópolis: Vozes, 2002, p.189-217.

BUTLER, Judith. Corpos que Pesam: sobre os limites discursivos do “sexo”. IN:LOURO, Guacira Lopes. (Org.) O Corpo Educado: pedagogias da sexualidade. Trad. Tomaz Tadeu da Silva. Belo Horizonte: Autêntica, 1999.

FACCHINI, Regina. Sopa de Letrinhas?: movimento homossexual e produção de identidades coletivas nos anos 1990. Rio de Janeiro: Garamond 2005.

GASTALDO, Édison. Publicidade e Sociedade: uma perspectiva antropológica. Porto Alegre: Sulina, 2013.

HALL, Stuart. Representation. Cultural Representation and Signifying Pratices. London: Sage/ Open University, 1997.

KATZ, Jonathan Ned. A Invenção da Heterossexualidade. Rio de Janeiro: Ed. Ediouro Publicações, 1996.

KIMMEL, M. A produção simultânea de masculinidades hegemônicas e subalternas. In: Horizontes Antropológicos, n. 9, ano 4, 1998.

LOURO, Guacira Lopes. Gênero, Sexualidade e Educação: uma perspectiva pós-estruturalista. Rio de Janeiro: Vozes, 1997

LOURO, Guacira Lopes. Teoria Queer: uma política pós-identitária para a educação. Revista Estudos Feministas, Florianópolis, V. 9, n. 2, p. 541-553, 2001. Disponível em <https:// periodicos.ufsc.br/index.php/ref/article/view/S0104-026X2001000200012/8865>. Acesso em: 22 nov. 2016.

MOSCOVICI, Serge. Representações sociais: investigações em psicologia social. Trad. de Pedrinho A. Guareschi. Petrópolis: Vozes, 2003.

NICHOLSON, Linda. Interpretando o gênero. Estudos Feministas. Ano 8. 2. ${ }^{\circ}$ semestre 2000. p. 09-41. Disponível na Internet http://www.portalfeminista.org.br., em 10 de janeiro de 2006.

RECUERO, Raquel. Um estudo do Capital Social gerado a partir de Redes Sociais no Orkut e nos Weblogs. Revista Famecos, n. 28, p. 88-106, dez., 2005.

RECUERO, Raquel. Redes Sociais na Internet. $2^{\mathrm{a}}$ ed. Porto Alegre: Sulina, 2014.

RODRIGUES, André Iribure. As representações das homossexualidades na publicidade e propaganda veiculadas na televisão brasileira: um olhar contemporâneo das últimas três décadas. 2008. Tese de Doutorado - Universidade Federal do Rio Grande do Sul. Disponível em $<$ http://www.lume.ufrgs.br/handle/10183/13806?locale=pt_BR $>$. Acesso em: 20 out. 2016. RODRIGUES, A. I.; TOALDO, M. M. Interação e Engajamento entre 
Marcas e Consumidores/Usuários no Facebook. Trabalho apresentado no GP Publicidade e Propaganda, XV Encontro dos Grupos de Pesquisas em Comunicação, evento componente do XXXVIII Congresso Brasileiro de Ciências da Comunicação. Rio de Janeiro, RJ - 4 a 7 de setembro de 2015.

TREVISAN, João Silvério. Devassos no paraíso: (a homossexualidade no Brasil, da colônia à atualidade). $6^{\mathrm{a}}$ ed. Rio de Janeiro: Record, 2004.

\section{Sobre o autor}

André Iribure. Professor Associado da Faculdade de Biblioteconomia e Comunicação na Universidade Federal do Rio Grande do Sul. Mestre em Comunicação e Informação e Doutor em Comunicação e Informação pela UFRGS, com Doutorado- sanduíche na UFRJ. Secretário de Comunicação da UFRGS. Este trabalho contou com a colaboração da bolsista de Iniciação Científica desta pesquisa, Katiúscia Machado (katiuscia.bmachado@gmail.com), graduanda em Comunicação Social - Publicidade e Propaganda pela Universidade Federal do Rio Grande do Sul. iribure@ufrgs.br 